Article

\title{
Ecofriendly Synthesis of Silver Nanoparticles Using Aqueous Extracts of Zingiber officinale (Ginger) and Nigella sativa L. Seeds (Black Cumin) and Comparison of Their Antibacterial Potential
}

\author{
Alaa H. Alkhathlan ${ }^{1}$, Hessah A. AL-Abdulkarim ${ }^{1}$, Mujeeb Khan ${ }^{1} \mathbb{D}$, Merajuddin Khan ${ }^{1}$, \\ Abdullah AlDobiy ${ }^{2}$, Musaed Alkholief 2,3 ${ }^{(D)}$, Aws Alshamsan 2,3 , Hamad Z. Alkhathlan 1,*(D) \\ and M. Rafiq H. Siddiqui ${ }^{1, *}$ \\ 1 Chemistry Department, College of Science, King Saud University, Riyadh 11451, Saudi Arabia; \\ aalkhathlan1@ksu.edu.sa (A.H.A.); hessah@ksu.edu.sa (H.A.A.-A.); kmujeeb@ksu.edu.sa (M.K.); \\ mkhan3@ksu.edu.sa (M.K.) \\ 2 Department of Pharmaceutics, College of Pharmacy, King Saud University, Riyadh 14511, Saudi Arabia; \\ 437105484@student.ksu.edu.sa (A.A.); malkholief@ksu.edu.sa (M.A.); aalshamsan@ksu.edu.sa (A.A.) \\ 3 Nanobiotechnology Unit, College of Pharmacy, King Saud University, Riyadh 14511, Saudi Arabia \\ * Correspondence: khathlan@ksu.edu.sa (H.Z.A.); rafiqs@ksu.edu.sa (M.R.H.S.)
}

Received: 5 October 2020; Accepted: 9 December 2020; Published: 16 December 2020

\begin{abstract}
Applications of chemical synthetic methods for the preparation of metal nanoparticles involve toxic reagents, which are hazardous to both humans and the environment. On the other hand, ecofriendly plant-based techniques offer rapid, non-toxic, and suitable alternatives to the traditional methods. Herein, we report an eco-friendly method for the preparation of silver nanoparticles (Ag NPs) using two different aqueous extracts of Zingiber officinale (ginger) and Nigella sativa L. seeds (black cumin). Successful preparation of Ag NPs was confirmed by X-ray diffraction, ultraviolet-visible (UV-Vis) spectroscopy, and energy dispersive spectroscopy (EDX). Transmission electron microscopy (TEM) analysis revealed that Nigella sativa L. seed extract (NSE) produced a smaller size of NPs $(\sim 8 \mathrm{~nm})$, whereas the ginger extract (GE) led to the formation of slightly larger Ag NPs ( 12 nm). In addition, to study the effect of concentration of the extract on the quality of resulting NPs, two different samples were prepared from each extract by increasing the concentrations of the extracts while using a fixed amount of precursor $\left(\mathrm{AgNO}_{3}\right)$. In both cases, a high concentration of extract delivered less agglomerated and smaller-sized Ag NPs. Furthermore, the antibacterial properties of as-prepared Ag NPs were tested against different bacterial strains. Notably, despite the slightly better quality of Ag NPs obtained from NSE (NSE-Ag), NPs prepared by using GE (GE-Ag) demonstrated superior antibacterial properties. In case of the plant-extract-based synthesis of nanoparticles, it is widely reported that during the preparation, the residual phytomolecules remain on the surface of resulting NPs as stabilizing agents. Therefore, in this case, the high antibacterial properties of GE-Ag can be attributed to the contributing or synergetic effect of residual phytomolecules of GE extract on the surface of Ag NPs, since the aqueous extract of GE has been known to possess higher intrinsic bactericidal properties when compared to the aqueous NSE extract.
\end{abstract}

Keywords: silver nanoparticles; Zingiber officinale; Nigella sativa L.; antibacterial

\section{Introduction}

Nanotechnology has become the focus of the scientific community due to the exciting properties of nanomaterials at the nanoscale, which differ from their bulk materials [1-4]. Metallic nanoparticles have 
attracted more interest of scientific researchers due to their various extraordinary properties, which has led to their application in several fields, like biomedicine, catalysis, preparation of nanocomposites with tunable electrical conductivity, thermal conductivity, tensile strength, superior rigidity, hardness, and erosion resistance, which can be used for manufacturing high-tech devices [5-10].

Different experimental approaches, often categorized as physical and chemical methods, have been used for the synthesis of nanomaterials, which is costly and involves toxic chemicals and hazardous conditions [11]. However, the development of simple and environmentally benign preparation protocols using non-toxic reagents and solvents under ambient conditions is highly desirable [12]. Several methods have been applied for the preparation of nanoparticles, including bioinspired approaches using natural products, such as micro- or marine organisms, proteins, and plant extracts (PEs), which have become popular for the synthesis of silver nanoparticles (Ag NPs) [13-15]. Of these, plant extracts have received much attention because they are easy to handle and due to their low cost [16]. Numerous research works have reported studies of the antibacterial, antifungal, and antimicrobial properties of Ag NPs obtained from different types of plant extracts [17-19]. In this regard, different types of spices have been traditionally used as therapeutic agents for a variety of pathogenic infections, including as antioxidant agents [20,21]. Different types of secondary metabolites (phytochemical constituents), such as anthocyanins, flavonoids, polyphenols, etc., which are present in spices are typically responsible for their unique aroma and flavor, and also contribute to their medicinal properties [22]. One example is the rhizome of the plant Zingiber officinale, which is commonly called ginger and is extensively consumed worldwide as a spice, delicacy, etc., and is also used for various medicinal purposes [23]. It belongs to the genus and family (Zingiberaceae). Ginger gets a pungent aroma from its volatile oil, gingerol, and other active components [24]. These bioactive constituents of ginger are known to inhibit prostaglandin and leukotriene formation by regulating the flow of blood, and they also control inflammation [25]. However, ginger typically exhibits moderate antioxidant properties against a variety of bacterial strains [26].

Another commonly used herbal seeds are black cumin seeds obtained from the Nigella sativa L. plant, which is an herbaceous plant belonging to the genus Ranunculaceae. This plant is indigenous to the Mediterranean region, but also has been cultivated in various parts of the world, including Saudi Arabia. The black seeds are commonly used as natural food additives and possess various medicinal properties, including insulinotropic, hypoglycemic, anticancer, antinociceptive, anti-inflammatory, hepatoprotective, neuroprotective, antihistamine, antiulcer, and bronchodilator properties [27]. However, the antibacterial properties of black cumin seeds have rarely been reported. For instance, Hosseinzadeh et al. evaluated the antimicrobial properties of total crude extracts and essential oil (EO) of Nigella sativa L. seeds against Staphylococcus aureus or Escherichia coli [28]. The results revealed that the aqueous extract did not show any inhibitory effect on either micro-organism; however, the chloroform extract of black seeds exhibited mild activity against the studied bacteria, whereas the EO of black seeds showed excellent antibacterial properties on Gram-positive and Gram-negative bacteria.

So far, a variety of plant extracts have been used to produce different types of novel nanomaterials, including Ag NPs, with diverse biological activities [29]. The plant extracts not only act as reducing agents, but also function as stabilizing agents; therefore, some of the residual phytomolecules remain attached to the surface of resulting nanoparticles (NPs) [30]. Therefore, it is commonly assumed that the intrinsic biological properties of plant extracts may further manifest in the biological activities of resultant NPs due to the combination of two components [31]. To further confirm this, herein, we have prepared Ag NPs using aqueous extracts of Zingiber officinale (ginger) and Nigella sativa L. seeds (black cumin) (Scheme 1). Synthesized Ag NPs were identified using X-ray diffraction, ultraviolet-visible (UV-Vis), Fourier-transform infrared (FT-IR), and transmission electron microscopy (TEM) analysis. In addition, the antimicrobial properties against various bacteria of the resultant $\mathrm{Ag}$ NPs obtained from both extracts were studied. 


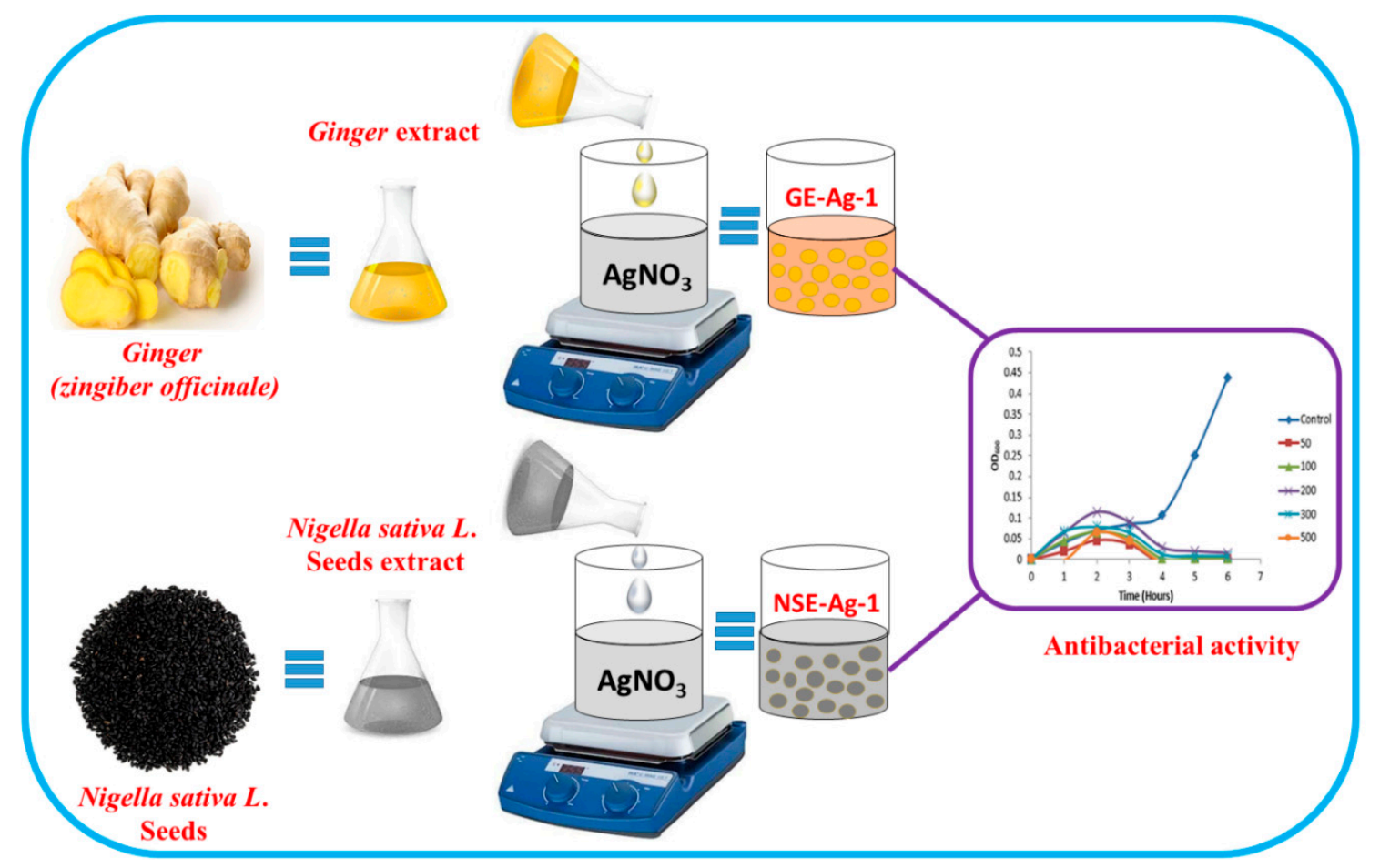

Scheme 1. Graphical representation of silver nanoparticles (Ag NPs) prepared using Nigella sativa L. seed extract (NSE) and (b) ginger extract (GE).

\section{Materials and Methods}

\subsection{Materials}

Both ginger and black cumin seeds were purchased from a local market in Riyadh, Saudi Arabia. They were identified by a botanical taxonomist from the Herbarium Division, College of Science, King Saud University, Riyadh, Saudi Arabia. The black cumin seeds were cultivated in the Al-Qassim region, Central Saudi Arabia.

Silver nitrate (AgNO3; 99.9\%) was purchased from Sigma-Aldrich Co (St. Louis, MO, USA).

\subsection{Preparation of Aqueous Extracts}

\subsubsection{Nigella sativa}

Freshly purchased seeds of Nigella sativa (black seeds) (30 g) were ground and boiled with $800 \mathrm{~mL}$ of deionized water. The resulting mixture was refluxed for $3 \mathrm{~h}$. Subsequently, the aqueous mixture was filtered using Whatman No. 1 filter paper and dried under reduced pressure in a rotary evaporator to give a dark-colored residue $(21.9 \mathrm{~g})$. A small amount of the powdery extract $(0.1 \mathrm{~g} / \mathrm{mL})$ was used for the synthesis of Ag NPs.

\subsubsection{Zingiber officinale}

Freshly purchased Z. officinale (ginger) (600 g) rhizomes were washed many times with DI (de-ionized)water to clean the dirt. The as-obtained material was chopped into small pieces and soaked in deionized water $(1000 \mathrm{~mL})$. The resulting aqueous mixture was refluxed for $3 \mathrm{~h}$. Subsequently, the mixture was filtered using Whatman No. 1 filter paper and dried under reduced pressure in a rotary evaporator to give a light-brown-colored residue $(5.7 \mathrm{~g})$, which was stored at $4{ }^{\circ} \mathrm{C}$ for further use. Using this aqueous-phase residue, a stock solution with an amount of $0.1 \mathrm{~g} / \mathrm{mL}$ of extract was prepared, which was used for the synthesis of silver nanoparticles. 


\subsection{Synthesis of Silver Nanoparticles}

A volume of $5 \mathrm{~mL}(5 \% \mathrm{v} / \mathrm{v})$ of aqueous black seed extract or aqueous ginger extract (obtained from separately prepared stock solutions) was taken in a round-bottom flask containing $99 \mathrm{~mL}$ of $10 \mathrm{mM}$ $(1.698 \mathrm{~g})$ aqueous $\mathrm{AgNO}_{3}$ solution. The flask was fitted with a condenser and a magnetic bar. The mixture was allowed to stir continuously for $3 \mathrm{~h}$ at $85{ }^{\circ} \mathrm{C}$. After some time, the color of the solution changed from light yellow to a reddish brown, which indicated the formation of nanoparticles. Subsequently, after $3 \mathrm{~h}$, the reaction stopped, and the resulting mixture was centrifuged at $9000 \mathrm{rpm}$ and washed repeatedly with distilled water to isolate pure Ag NPs.

To study the effect of the concentration of Nigella sativa L. seed extract (NSE) and ginger (GE) on the quality of the resulting NPs, various experiments were performed by mixing $1(1 \% v / v), 2.5(2.5 \% v / v)$, $5(5 \% v / v), 7.5(7.5 \% v / v)$, and $10(10 \% v / v) \mathrm{mL}$ of the each extract and $10 \mathrm{mM}$ of $\mathrm{AgNO}_{3}$, with a total volume of $100 \mathrm{~mL}$. Similarly, to study the effect of $\mathrm{AgNO}_{3}$, the amounts of aqueous extracts were kept constant at $5(5 \% \mathrm{v} / \mathrm{v}) \mathrm{mL}$, but the concentration of silver nitrate was varied in each experiment $(5,10$, 15 , and $20 \mathrm{mM}$ ), keeping the total volume constant at $100 \mathrm{~mL}$ and temperature at $85^{\circ} \mathrm{C}$.

\subsection{Characterization of Silver Nanoparticles}

The optimal measurements of the synthesized Ag NPs recorded at different time intervals were recorded with a UV-1800 UV-Vis spectrophotometer (Shimadzu, Kyoto, Japan). They were performed in quartz cuvettes, and the scale of the wavelength was set between 300 and $550 \mathrm{~nm}$. X-ray powder diffraction (XRD) was measured with $\mathrm{Cu} \mathrm{K} \alpha$ radiation $(\lambda=1.5418 \AA$ ) using an Ultima IV X-ray powder diffractometer (Rigaku, Tokyo, Japan). High-resolution transmission electron microscopy (HRTEM) and energy-dispersive X-ray spectroscopy (EDX) (JEM 2100F (JEOL, Tokyo, Japan)) were used. The accelerating voltage used for TEM measurements was $200 \mathrm{kV}$. FT-IR measurements were performed using a Perkin-Elmer 1000 infrared (IR) spectrometer (Waltham, MA, USA). To remove the unbound free residual extract entities from the surface of Ag NPs, the as-obtained Ag NPs were suspended in DI water; the mixture was stirred for couple of minutes and subsequently centrifuged at $9000 \mathrm{rpm}$ for $30 \mathrm{~min}$. This process was repeated several times to ensure better purification of the Ag NPs. The purified Ag NPs were mixed with KBr powder and pressed into pellets for measurement. Background correction was performed using a blank reference $\mathrm{KBr}$ pellet.

\subsection{Antibacterial Properties}

\subsubsection{Bacterial Culture}

Standard bacterial cultures were obtained from the American Type Culture Collection (ATCC)/National Collection of Type Culture (NCTC), while methicillin resistant Staphylococcus aureus (MRSA) and extended-spectrum beta lactamase E. coli (ESBL) culture were obtained from the Microbiology Unit, Department of Pharmaceutics, College of Pharmacy, King Saud University, Riyadh, Saudi Arabia. The growth inhibition of bacterial strains (two Gram positive and two Gram negative) was checked against different concentrations of silver compounds at different time points. Two Gram-positive bacteria (Staphylococcus aureus and Bacillus subtilis) and two Gram-negative bacteria (Escherichia coli and Pseudomonas aeruginosa) were procured from the culture collection of the Microbiology Department at the College of Pharmacy, King Saud University, and their identification was performed through standard biochemical and microbiological methods. The bacteria were initially grown in Muller Hinton Agar at $37^{\circ} \mathrm{C}$ overnight. The active growth of bacteria was again transferred to Muller Hinton broth and grown at $37^{\circ} \mathrm{C}$ overnight in order to get active bacteria.

\subsubsection{Preparation of Compounds for Antibacterial Activity}

The as-obtained Ag NPs (NSE-Ag-1 and 2 and GE-Ag-1 and 2) were initially solubilized in deionized water using sonication. The initial concentration of samples was adjusted to $10 \mu \mathrm{g} / \mu \mathrm{L}$. 
From this stock, the concentration of Ag NPs was later adjusted to 500, 300, 200, 100, 50, and $0 \mu \mathrm{g} / \mathrm{mL}$ in Muller Hinton broth.

\subsubsection{Antimicrobial Activity of Ag NPs through Optical Density}

The effect of Ag NPs on the growth of S. aureus, B. subtilis, E. coli, and P. aeruginosa was determined. The antibacterial activity was determined through measurement of bacterial growth at different time points against different concentrations of compounds. The growth of bacteria was determined through measurement of optical density at $600 \mathrm{~nm}$ using a microplate reader (BioTek, Winooski, VT, USA). The overnight bacterial culture was diluted 3-10 times; $5 \mu \mathrm{L}$ of this bacterial suspension was added to media containing different concentrations of $\mathrm{Ag}$ NPs and incubated at $37^{\circ} \mathrm{C}$. The $\mathrm{OD}_{600}$ (optical density) was recorded at different time points ranging from $0-7 \mathrm{~h}$. The graph of OD600 vs. time was plotted to evaluate the effects of Ag NPs on the growth of bacteria. All readings were calculated after reducing OD600 at $0 \mathrm{~h}$ from the given time point.

\section{Results and Discussion}

In this work, silver nanoparticles (Ag NPs) were prepared using the aqueous extracts of $Z$. officinale (ginger-GE) and Nigella Sativa (black seeds-NSE). The reactions were performed under facile conditions using an aqueous solution of $\mathrm{AgNO}_{3}$ precursor salt and GE or NSE extracts without addition of any other external reducing agents. In order to study the effect of the concentration of the extracts on the quality of resulting NPs and their antibacterial properties, each extract was used to prepare two different samples of Ag NPs by varying the concentrations of the extracts, such as $5 \mathrm{~mL}$ $(5 \% v / v)$ and $10 \mathrm{~mL}(10 \% v / v)$, while keeping the amount of $\mathrm{AgNO}_{3}$ constant at $10 \mathrm{mM}$. The samples prepared using $5 \mathrm{~mL}(5 \% \mathrm{v} / \mathrm{v})$ of GE extract and $10 \mathrm{mM}$ of $\mathrm{AgNO}_{3}$ were named GE-Ag-1, whereas NPs obtained via $10 \mathrm{~mL}(10 \% v / v)$ of GE and $10 \mathrm{mM}$ of $\mathrm{AgNO}_{3}$ were called GE-Ag-2. Similarly, Ag NPs obtained from a low concentration $(5 \mathrm{~mL}(5 \% v / v))$ and high concentration $(10 \mathrm{~mL}(10 \% v / v))$ of NSE extract-using same amount of $\mathrm{AgNO}_{3}(10 \mathrm{mM})$ - were called NSE-Ag-1 and NSE-Ag-2, respectively.

\subsection{UV-Vis Spectroscopic Analysis}

The color of the aqueous solution of $\mathrm{AgNO}_{3}$ gradually changed from light yellow to dark brown upon addition of the GE or NSE extracts while stirring for several hours. This clearly indicated the formation of Ag NPs, which is a typical characteristic of Ag and is reflected by its surface plasmon resonance. Figure 1 displays the UV-Vis spectra of the synthesized Ag NPs at $90{ }^{\circ} \mathrm{C}$ using both GE (cf. Figure 1a) and NSE (cf. Figure 1b) extracts. The quality of the resultant Ag NPs is often reflected by the shape and position of surface plasmon resonance (SPR) band; a sharp band at a lower wavelength represents a smaller size of NPs [32]. The UV absorption peak of GE-Ag-1 appeared at $\sim 430 \mathrm{~nm}$, whereas NSE-Ag-1 exhibited an absorption peak at $\sim 410 \mathrm{~nm}$. This slight variation $(\sim 20 \mathrm{~nm})$ in the positions of UV peaks of Ag NPs prepared by using low concentrations of GE and NSE extracts can be attributed to the quality of the resulting NPs. Thus, it can be inferred that GE produced a slightly larger size of NPs when compared to NSE. Similarly, upon increasing the concentrations of extracts from 5 to $10 \mathrm{~mL}$, the respective absorption peaks were slightly shifted to lower wavelengths in both cases (GE and NSE). The UV peak of GE-Ag-2 was shifted from $\sim 430$ to $\sim 425 \mathrm{~nm}$, whereas NSE-Ag-2 moved to $\sim 405 \mathrm{~nm}$. This can be attributed to the high concentrations of the extracts, which may provide better stabilization of resultant NPs. Similar observations were made in our recent study on the synthesis of Ag and Au NPs using an aqueous extract of the Pulicaria undulata plant [33]. At lower concentrations of plant extract, irregularly shaped Ag and Au NPs were obtained, whereas at higher concentrations, isotropic, spherically shaped $\mathrm{Ag}, \mathrm{Au}$, and $\mathrm{Au}-\mathrm{Ag}$ alloy NPs were formed due to the presence of sufficient concentrations of ligands for stabilizing the surface energy of the nuclei. Apart from concentration, other factors including the temperature, types of solvents, $\mathrm{pH}$ of the reaction medium, etc. may also exert considerable effects on the quality of the final product, which we plan to study in our future work. 

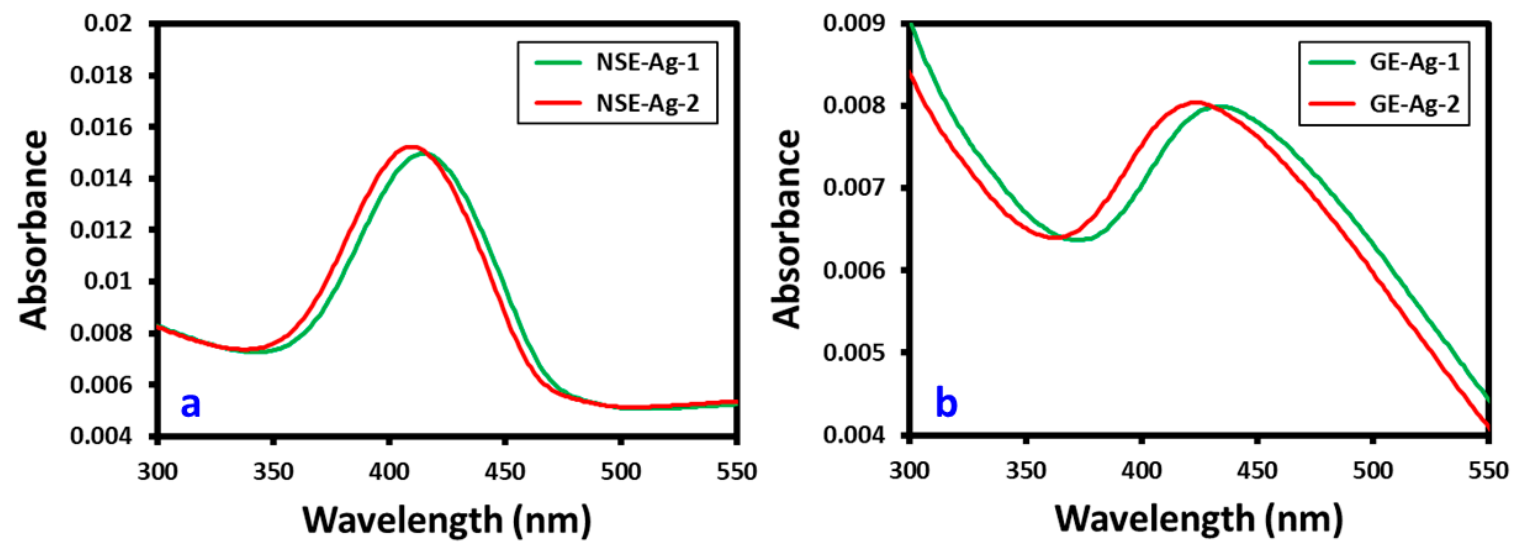

Figure 1. Ultraviolet-visible (UV-Vis) absorption spectra of silver nanoparticles prepared using (a) low (5 mL, NSE-Ag-1) and high concentrations (10 mL, NSE-Ag-2) of NSE and (b) low (5 mL, GE-Ag-1) and high concentrations $(10 \mathrm{~mL}, \mathrm{GE}-\mathrm{Ag}-2)$ of GE.

\subsection{FT-IR Analysis}

The dual roles of the NSE and GE as bio-reductant and capping agents were confirmed through FT-IR analysis of the as-prepared Ag NPs. The NP samples for the infrared analysis were carefully prepared to exclude any possibility of the presence of any unbound phytomolecules of extract residue. In order to do this, after the final workup, the as-prepared Ag NPs were redispersed in distilled water via $30 \mathrm{~min}$ of sonication, and were subsequently centrifuged at a speed of $9000 \mathrm{rpm}$ for $30 \mathrm{~min}$; this process was repeated twice to isolate the pure NPs and exclude the presence any unbound ligands. The FT-IR spectra of pure GE and NSE re provided in the supplementary information (Figure S1). The FT-IR spectrum of the GE-Ag-1 in Figure 2 indicates the presence of various types of polyphenols. For instance, the presence of a strong broad band at $3447 \mathrm{~cm}^{-1}$ can be attributed to $-\mathrm{OH}$ stretching vibrations. The combination of various peaks with strong to medium intensities in the regions between 2500 and $3500 \mathrm{~cm}^{-1}\left(\mathrm{O}-\mathrm{H}\right.$ stretch), 2500 and $2800 \mathrm{~cm}^{-1}$ (overtone and combination bands), and $1712 \mathrm{~cm}^{-1}$ indicates the presence of a carbonyl group. Other strong- to medium-intensity bands were also observed at 2922 and $2857 \mathrm{~cm}^{-1}$, suggesting the presence of a hydrocarbon C-H group. Some other bands appeared at 1636 and $1609 \mathrm{~cm}^{-1}, 1514$ and $1459 \mathrm{~cm}^{-1}, 1375 \mathrm{~cm}^{-1}, 1272 \mathrm{~cm}^{-1}$, $1159 \mathrm{~cm}^{-1}, 1037 \mathrm{~cm}^{-1}$, and $618 \mathrm{~cm}^{-1}$, which might be due to the presence of $\mathrm{CH}_{2}=\mathrm{CH}_{2}$, aromatic $\mathrm{C}=\mathrm{C}$, alkene, methyl $-\mathrm{CH}_{3}$, ether, alcohol, and phenols, respectively. As a support for the above assumption, a GC/MS (gas chromatography/mass spectrometry) analysis for the GE extract showed the presence of two major components, 6-gingerol and 6-shogaol. Similarly, the IR spectrum of NSE-Ag-1 also indicated the presence of flavonoids and polyphenols due to the existence of various absorption peaks belonging to the $\mathrm{OH}$ of the carboxylic group, such as the absorption peaks at $3448 \mathrm{~cm}^{-1}$ corresponding to the hydrogen-bonded hydroxyl $(\mathrm{OH})$ and the peak at $2943 \mathrm{~cm}^{-1}$, which indicated the presence of $\mathrm{C}-\mathrm{H}$. The absorption peaks situated around 1641 and $1402 \mathrm{~cm}^{-1}$ are the characteristic peaks for the $\mathrm{C}=\mathrm{O}$ and $\mathrm{C}=\mathrm{C}$ stretching, respectively, of the aromatics. These peaks indicate the presence of phytomolecules of GE and NSE on the surface of the resulting Ag NPs. Again, as a support for this assumption, a GC/MS analysis of the NSE and GE extracts suggested the presence of various components, including hexanal, palmitic acid, and other hydroxyl groups containing compounds that are traditionally known to be reducing agents; however, more advanced characterizations are still required to identify other responsible phytomolecules. 

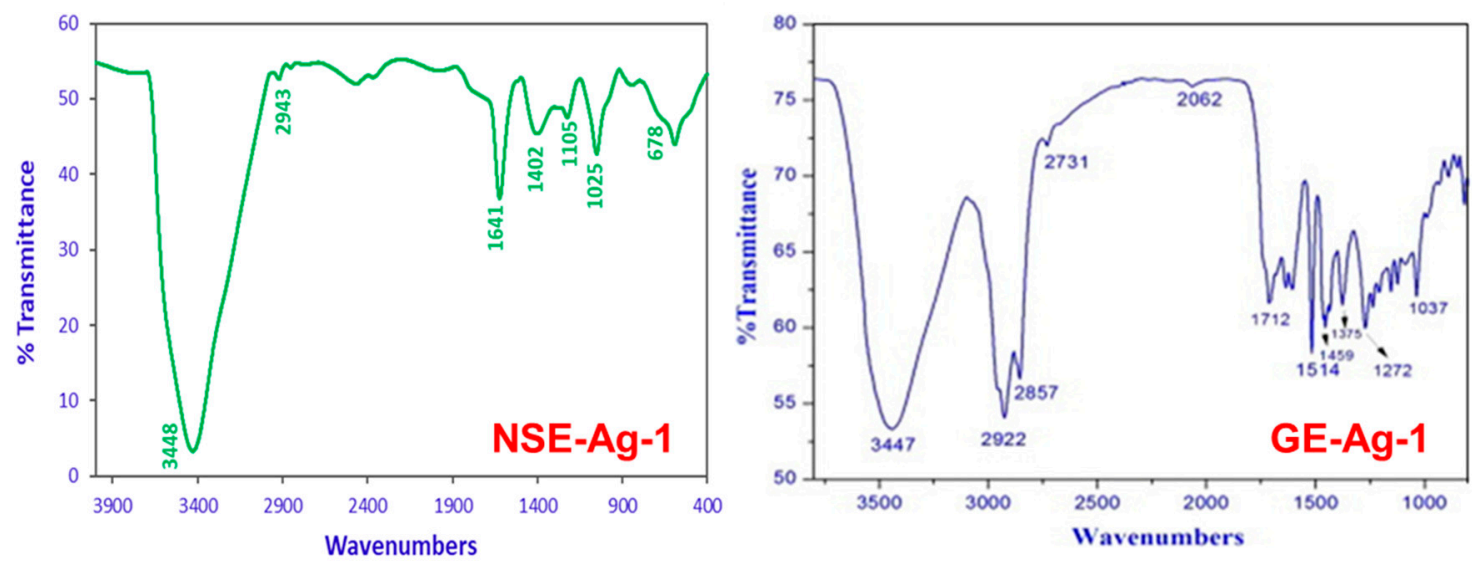

Figure 2. Fourier-transform infrared (FT-IR) spectra of NSE-Ag-1 and GE-Ag-1.

\subsection{XRD Analysis}

The formation of Ag NPs using both NSE and GE and the crystalline nature of the resultant samples were confirmed from the analysis of the X-ray diffraction (XRD) patterns. In the case of Ag NPs prepared from GE (GE-Ag-1), the XRD pattern in Figure 3a,b indicates the presence of a face-centered cubic $(f c c)$ structure. There are five distinct reflections in the spectrum at $38.50^{\circ}(111), 44.13^{\circ}(200)$, $64.91^{\circ}(220), 77.89^{\circ}(311)$, and $81.13^{\circ}(222)$. The (111) facet is the most dominant phase in the crystal structure of the as-obtained Ag NPs; this is clearly indicated by the presence of the most intense peak at $38.50^{\circ}$ as compared to the other reflections in the XRD pattern, as shown in Figure 3. Similar reflections were also found in the XRD spectra of Ag NPs (Figure 3c,d) synthesized from NSE, which confirmed the identity of Ag NPs synthesized from both extracts. Notably, in the XRD spectra of all the samples of as-prepared Ag NPs, some additional reflections were found apart from the reflections belonging to Ag NPs. The presence of these additional reflections is attributed to the inorganic residual moieties of the extract. The results show that the main phase is silver, whereas the additional peaks may have originated from other crystalline phases belonging to the inorganic moieties of the extract, which also contribute to the XRD pattern as impurities. For instance, several other studies regarding the green synthesis of Ag NPs using plant extracts have also reported the existence of similar extra peaks in the XRD patterns of Ag NPs [34]. These peaks were attributed to the crystalline impurities (salts or minerals based on metals such as calcium, magnesium, potassium, etc.) of the left-over leaf extracts present on the surface of the resultant nanoparticles [35].

\subsection{EDS Analysis}

The elemental compositions of the as-prepared samples of Ag NPs were also determined by EDX (energy dispersive X-ray spectrometry). The EDS spectra shown in Figure S2 (Supplementary Information) reveal the clear elemental composition profile of the green synthesized Ag NPs using both GE and NSE. Figure S2 (GE-Ag-1) shows the EDS signals of silver nanoparticles prepared from $5 \mathrm{~mL}$ GE and $10 \mathrm{mM}$ of silver precursor salt. The NSE-Ag- 1 sample was prepared using $5 \mathrm{~mL}(5 \% \mathrm{v} / \mathrm{v})$ of NSE and $10 \mathrm{mM}$ of silver precursor salt. In both spectra, the intense signal at $3 \mathrm{keV}$ strongly suggests that $\mathrm{Ag}$ was the major element, which has an optical absorption in this range due to the surface plasmon resonance (SPR) [36]. The other signals in the range of $0.0-0.5 \mathrm{keV}$ typically represent the absorption of carbon and oxygen, and thus indicate the presence of the extract (as a capping ligand) on the surfaces of the NPs. However, in some cases, these peaks are not visible clearly, as in the case of NSE-Ag-2 (Supplementary Information, Figure S2). Similarly, as shown in the spectra of GE-Ag-2 and NSE-Ag-2 (Figure S2), the presence of Ag NPs is also confirmed in the samples prepared by using a higher concentration $(10 \mathrm{~mL}(10 \% v / v))$ of GE and NSE. 

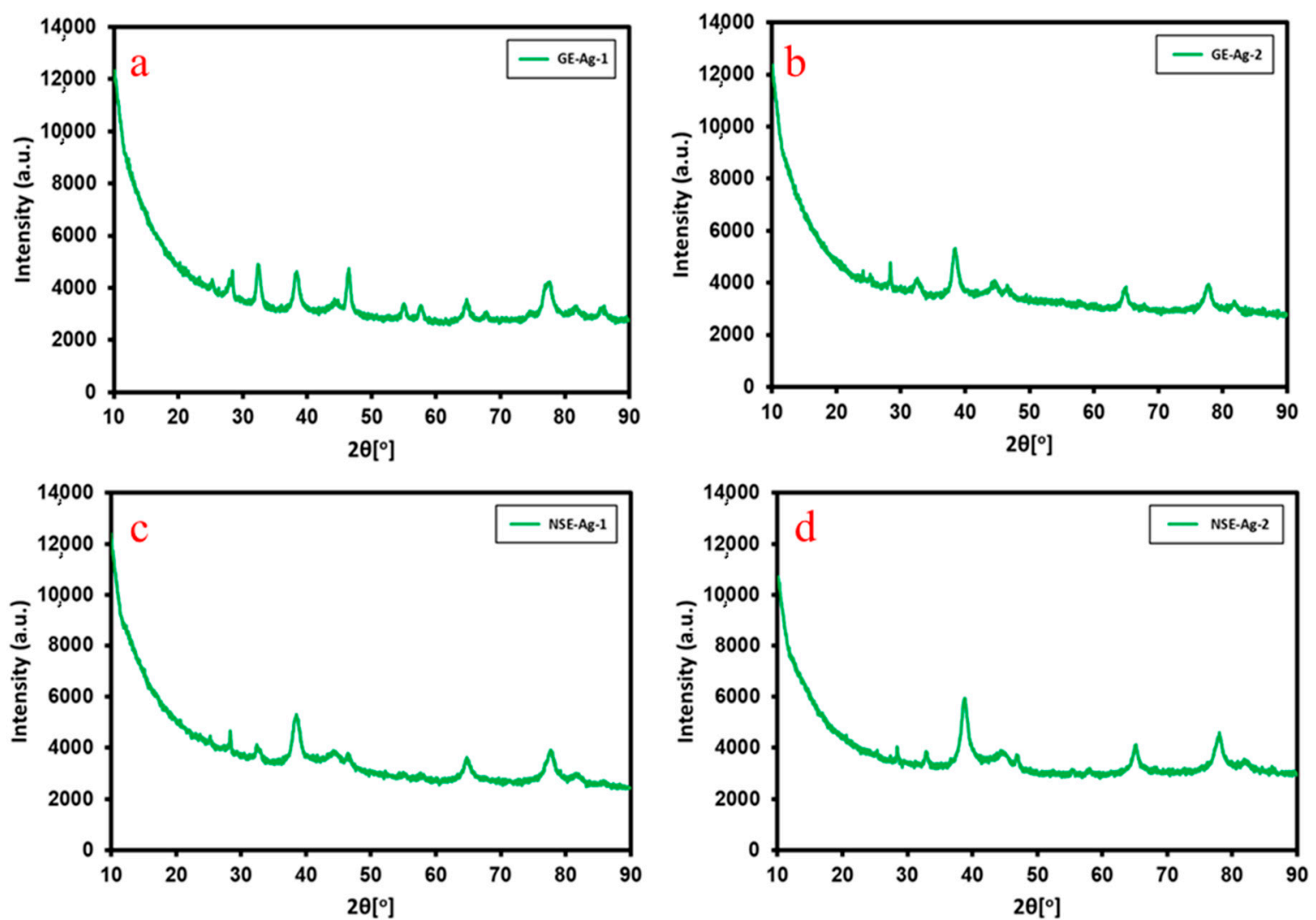

Figure 3. X-ray diffraction (XRD) pattern of the Ag NPs prepared by using (a) $5 \mathrm{~mL}$ and (b) $10 \mathrm{~mL}$ of GE extract, whereas, (c) $5 \mathrm{~mL}$ and (d) $10 \mathrm{~mL}$ of NSE extract keeping amount of $\mathrm{AgNO}_{3}$ constant at $10 \mathrm{mM}$.

\subsection{TEM Analysis}

The size and morphology of the resultant Ag NPs prepared with different concentrations of GE and NSE and with fixed amounts of metal precursors were evaluated using transmission electron microscopy (TEM). Figure 4 shows an overview of the green synthesized Ag-NPs using $5 \mathrm{~mL}(5 \% v / v)$ of GE (GE-Ag-1), which clearly points towards the spherical morphology of the NPs, which had an average size of $\sim 14 \mathrm{~nm}$. Mostly, the NPs are well distributed; however, a few of them were found to be agglomerated. It was revealed that the size of NPs slightly decreased with an increase in the amount of GE from 5 to $10 \mathrm{~mL}$ (GE-Ag-2). In this case, the mean size of the resultant NPs decreased from $~ 14$ to $\sim 12 \mathrm{~nm}$ (Figure 4). Similarly, the concentration of NSE also had a significant effect on the size and agglomeration of the resultant NPs. When $5 \mathrm{~mL}$ of NSE was used and the amount of silver salt was fixed, such as with $10 \mathrm{mM}$ (Figure 5, NSE-Ag-1) and $10 \mathrm{~mL}$ (Figure 5, NSE-Ag-2), spherically shaped NPs were obtained, and the size of the NPs changed from $\sim 12$ to $\sim 8 \mathrm{~nm}$. Notably, the concentration of the PEs also affected the polydispersity of the NPs; for example, a low concentration $(5 \% v / v)$ of PE rendered a high degree of polydispersity, while at a higher concentration $(10 \% v / v)$, samples with less polydispersity were obtained. For instance, using $5 \mathrm{~mL}$ of both GE (GE-Ag-1) and NSE (NSE-Ag-1) produced Ag NPs in the size ranges of 5-40 and 5-35 nm, respectively (Figures 4 and 5). On the other hand, using $10 \mathrm{~mL}$ of GE (GE-Ag-2) and NSE (NSE-Ag-2), Ag NPs within the size ranges of $\sim 5-20$ and $\sim 5-15 \mathrm{~nm}$ were obtained. Therefore, the TEM analysis of samples prepared from both GE and NSE clearly indicates that both extracts produced high-quality, smaller-sized NPs with slight variation in their sizes. 

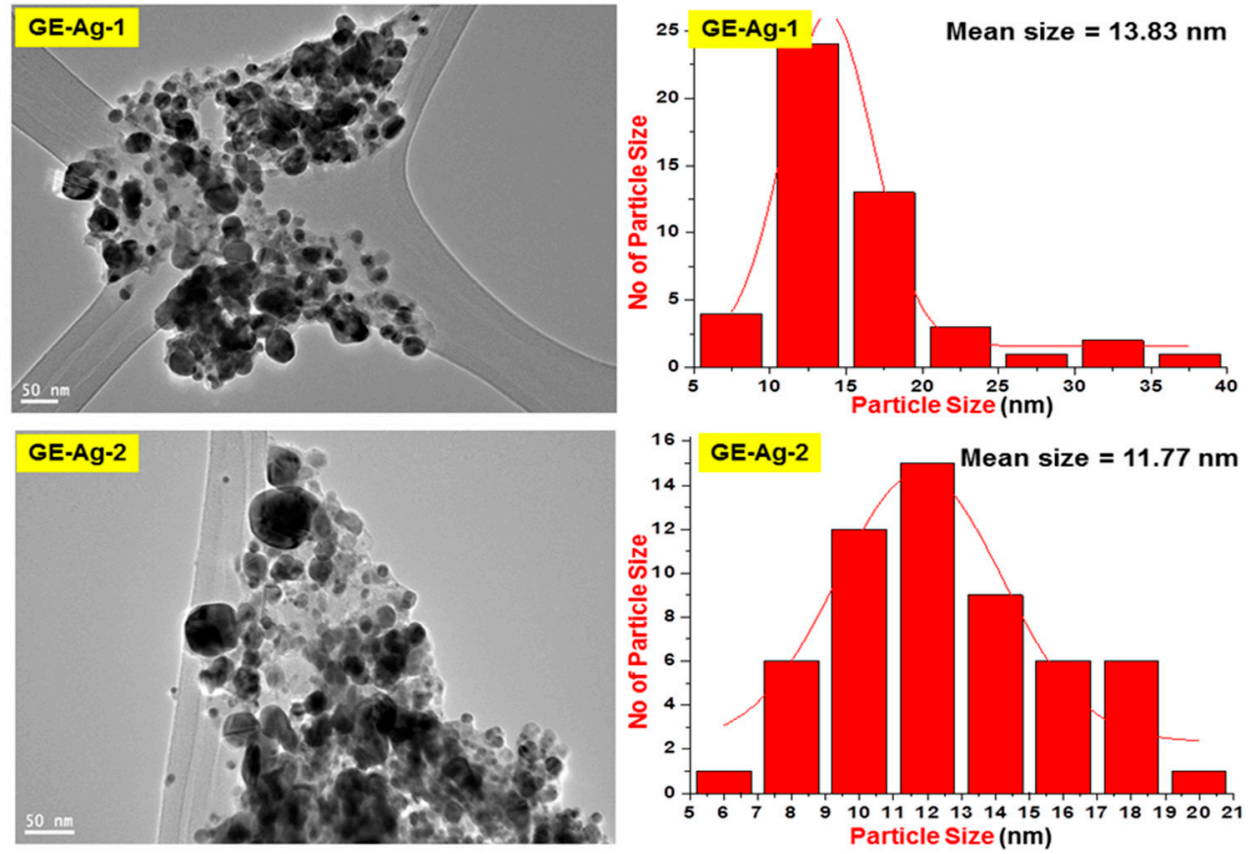

Figure 4. Transmission electron microscopy (TEM) images of green synthesized Ag NPs using low (5 mL, GE-Ag-1) and high (10 mL, GE-Ag-2) concentrations of GE.
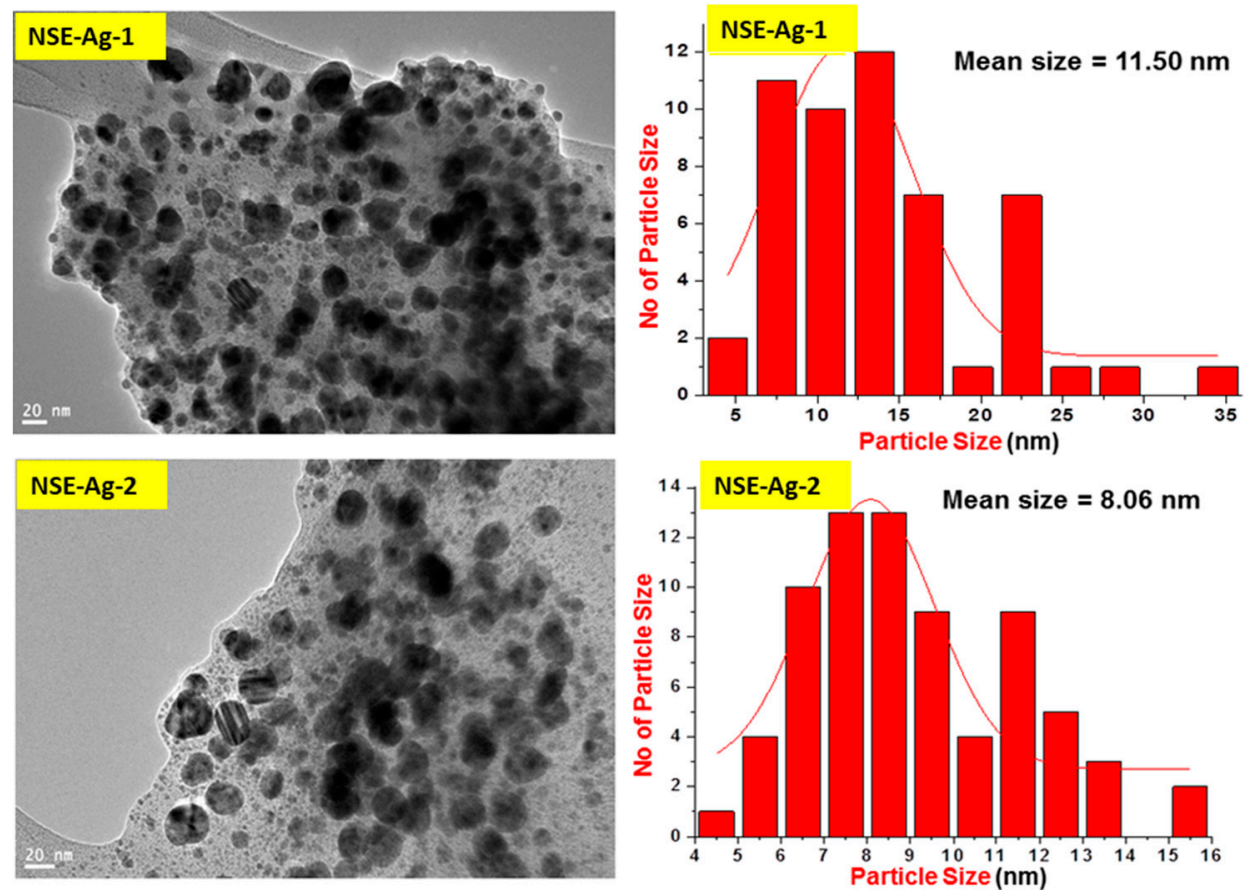

Figure 5. TEM images of green synthesized Ag NPs using low (5 mL, NSE-Ag-1) and high (10 mL, NSE-Ag-2) concentrations of NSE.

\subsection{Antibacterial Study}

Preliminary results on growth inhibition were obtained by determining the OD600 of bacteria grown with various concentrations of green synthesized Ag NPs $(50-500 \mu \mathrm{g} / \mathrm{mL})$. The antibacterial activities of resultant Ag NPs prepared from different extracts (GE and NSE) were measured against four bacterial strains from both Gram-negative (Escherichia coli and Pseudomonas aeruginosa) and Gram-positive (Staphylococcus aureus and Bacillus subtilis) bacteria. The results indicated that only Ag NPs prepared from GE demonstrated excellent antibacterial activity against all four species of 
bacteria tested. Although the Ag NPs prepared from GE were slightly larger in size ( 12-14 nm) when compared to NPs obtained from NSE ( 8-12 nm), the former NPs demonstrated enhanced antibacterial properties. The antibacterial activity of GE-capped Ag NPs prepared with various concentrations of GE with a fixed amount of silver precursor was measured against E. coli, P. aeruginosa, S. aureus, and B. subtilis. The effects of capped Ag NPs $(50-500 \mu \mathrm{g} / \mathrm{mL})$ prepared with $5 \mathrm{~mL}$ of GE and $10 \mathrm{mM}$ of $\mathrm{AgNO}_{3}$ (GE-Ag-1) on the growth of four different organism are shown in Figure 6. From the results presented in Figure 6, it was observed that a concentration of $50 \mu \mathrm{g} / \mathrm{mL}$ was optimal for determining the effect of the addition of GE on the antimicrobial properties of Ag-NPs. The sample of Ag NPs prepared using $5 \mathrm{~mL}$ of extract demonstrated antibacterial activity in the following order: P. aeruginosa $>$ E. coli $>$ B. subtilis $>$ S. aureus.
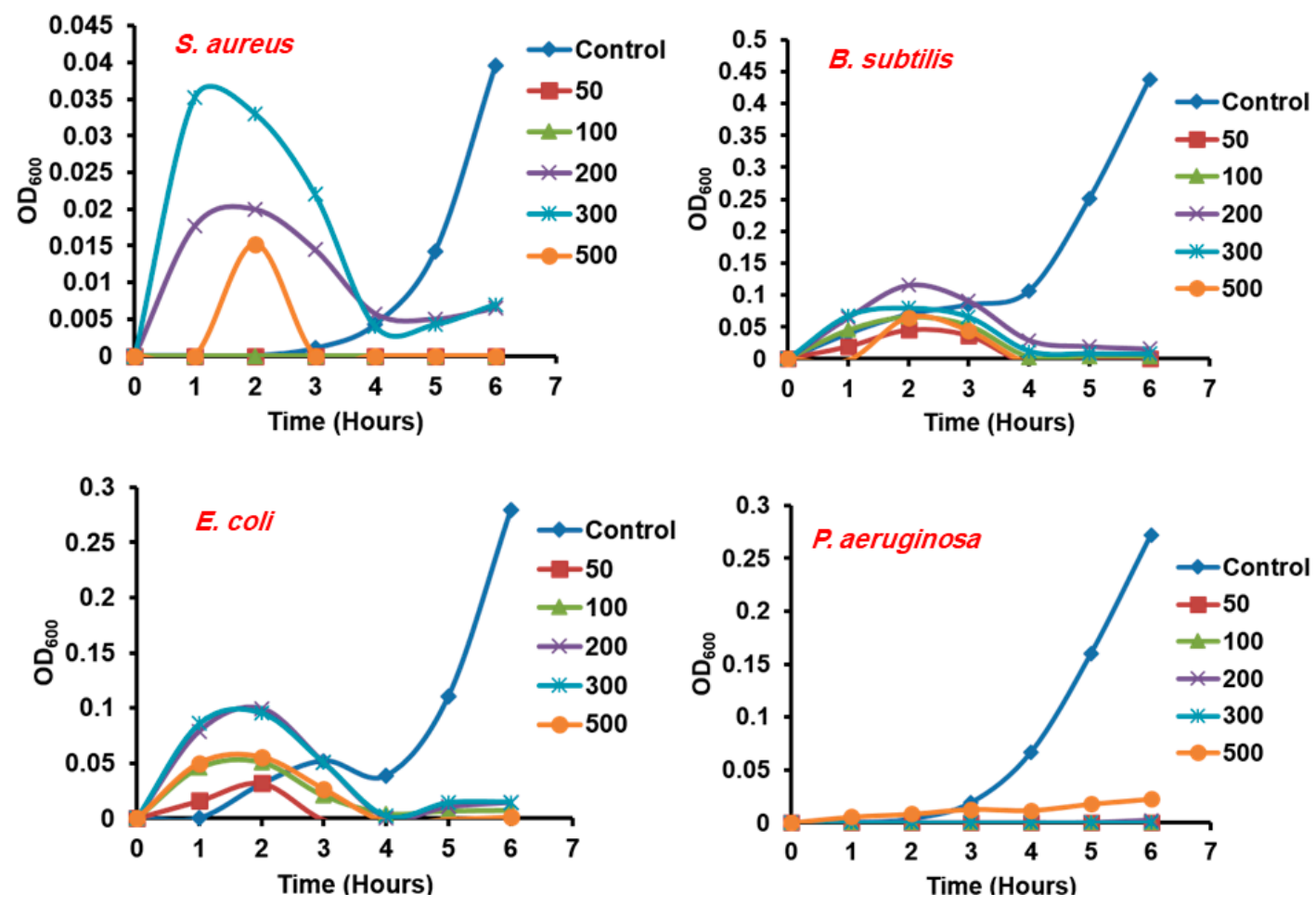

Figure 6. Antibacterial activity of Ag NPs prepared from GE using $5 \mathrm{~mL}$ of GE and $10 \mathrm{mM}$ of $\mathrm{AgNO}_{3}$ (GE-Ag-1) against different bacterial strains.

However, when the Ag NPs were prepared by increasing the concentration of the GE from 5 to $10 \mathrm{~mL}$ and using $10 \mathrm{mM}$ of precursor (GE-Ag-2, cf. Figure 7), the resultant sample demonstrated excellent antibacterial activities against all the bacteria tested. This sample also exhibited considerable activity towards S. aureus, against which the other sample showed the least antibacterial activity. In general, from the results, it is evident that the Ag NPs prepared using a lower concentration of GE $(5 \mathrm{~mL})$ did not exhibit good antimicrobial activity against the Gram-positive bacterial strains (Staphylococcus aureus and Bacillus subtilis) tested in this study, up to a concentration of $500 \mu \mathrm{g} / \mathrm{mL}$. In comparison, these amples demonstrated slightly better antibacterial activities towards Gram-negative bacterial strains, including Escherichia coli and Pseudomonas aeruginosa. However, the toxicity/antimicrobial activity of Ag NPs $(50 \mu \mathrm{g} / \mathrm{mL})$ increased with increasing concentrations of GE used in their preparation, which can be a result of the increased solubility of the resultant Ag NPs due to the better stabilization of NPs at higher concentrations of the extract. 

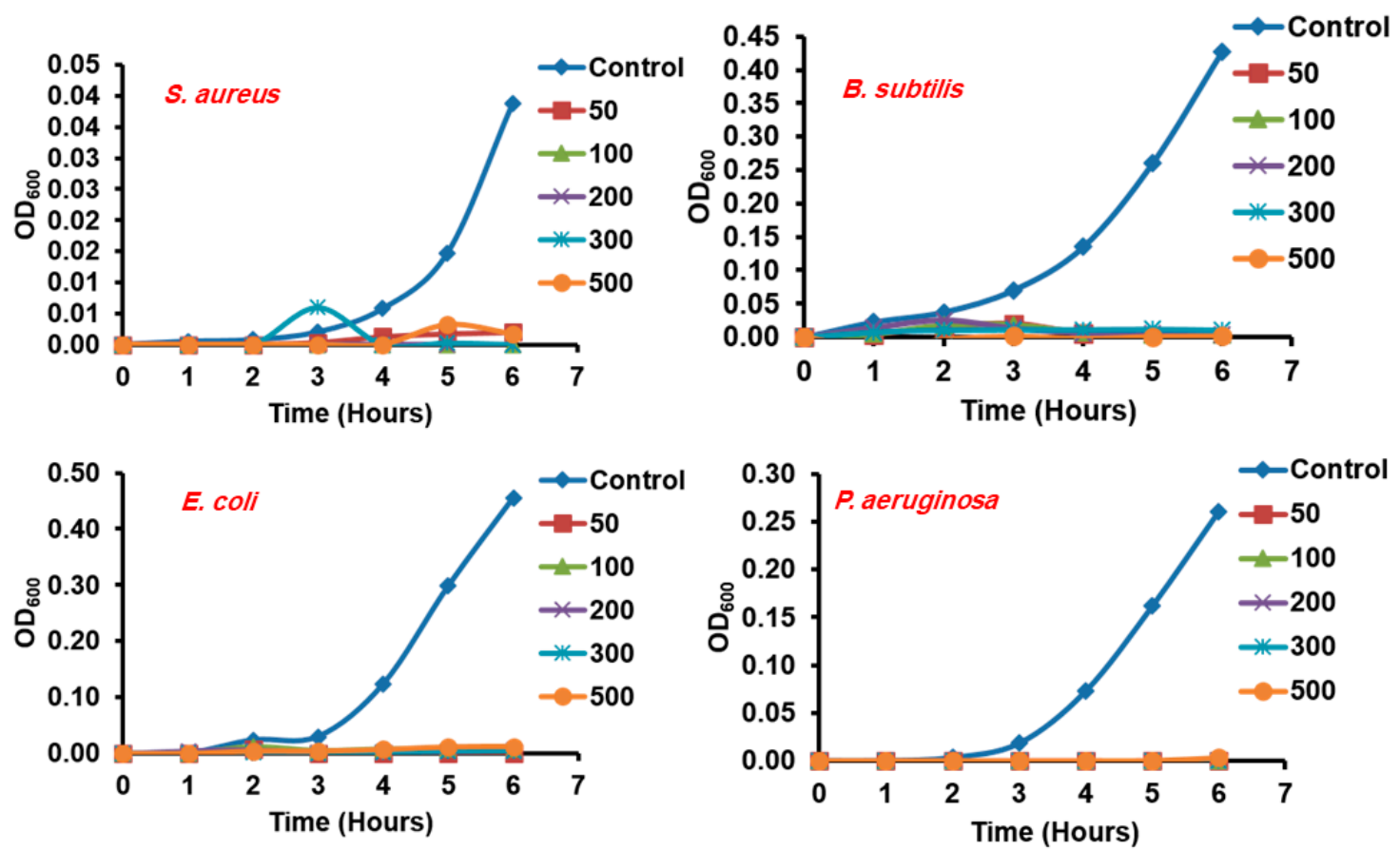

Figure 7. Antibacterial activity of Ag NPs prepared from GE using $10 \mathrm{~mL}$ of GE and $10 \mathrm{mM}$ of $\mathrm{AgNO}_{3}$ (GE-Ag-2) against different bacterial strains.

Similarly, the antibacterial properties of Ag NPs prepared from both low (NSE-Ag-1, cf. Figure 8) and high (NSE-Ag-2, cf. Figure 9) concentrations of NSE were also tested on all aforementioned bacterial strains. Notably, both NSE-Ag-1 and NSE-Ag-2 demonstrated far fewer inhibiting properties against all tested bacterial strains when compared to GE-Ag-1 and GE-Ag-2. However, between the samples obtained from NSE, NSE-Ag-2 (Figure 9) demonstrated slightly better antibacterial activity than NSE-Ag-1 (Figure 8), as occurred in the case of Ag NPs prepared from GE. This clearly implies that high concentrations of the extract contribute to the enhancement of bacterial inhibition properties due to the better solubilization of NPs due to the presence of a higher number of residual phytomolecules on the surface of the resulting NPs [37].

Generally, the antibacterial properties of NPs obtained from plant extracts depend on various factors, including the size, shape, and agglomeration of NPs [38]. In this case, we believe that, apart from the size and agglomeration of NPs, the antibacterial properties of the resulting Ag NPs also depend on the intrinsic bactericidal properties of the plant extracts. Various reports have suggested that aqueous ginger extract demonstrated much better antibacterial properties when compared to aqueous extract of black seeds, which often did not show any effects on the studied bacteria $[39,40]$. Therefore, the high antibacterial activity of Ag NPs obtained from GE can be attributed to the higher intrinsic bactericidal effect of aqueous ginger extract. 

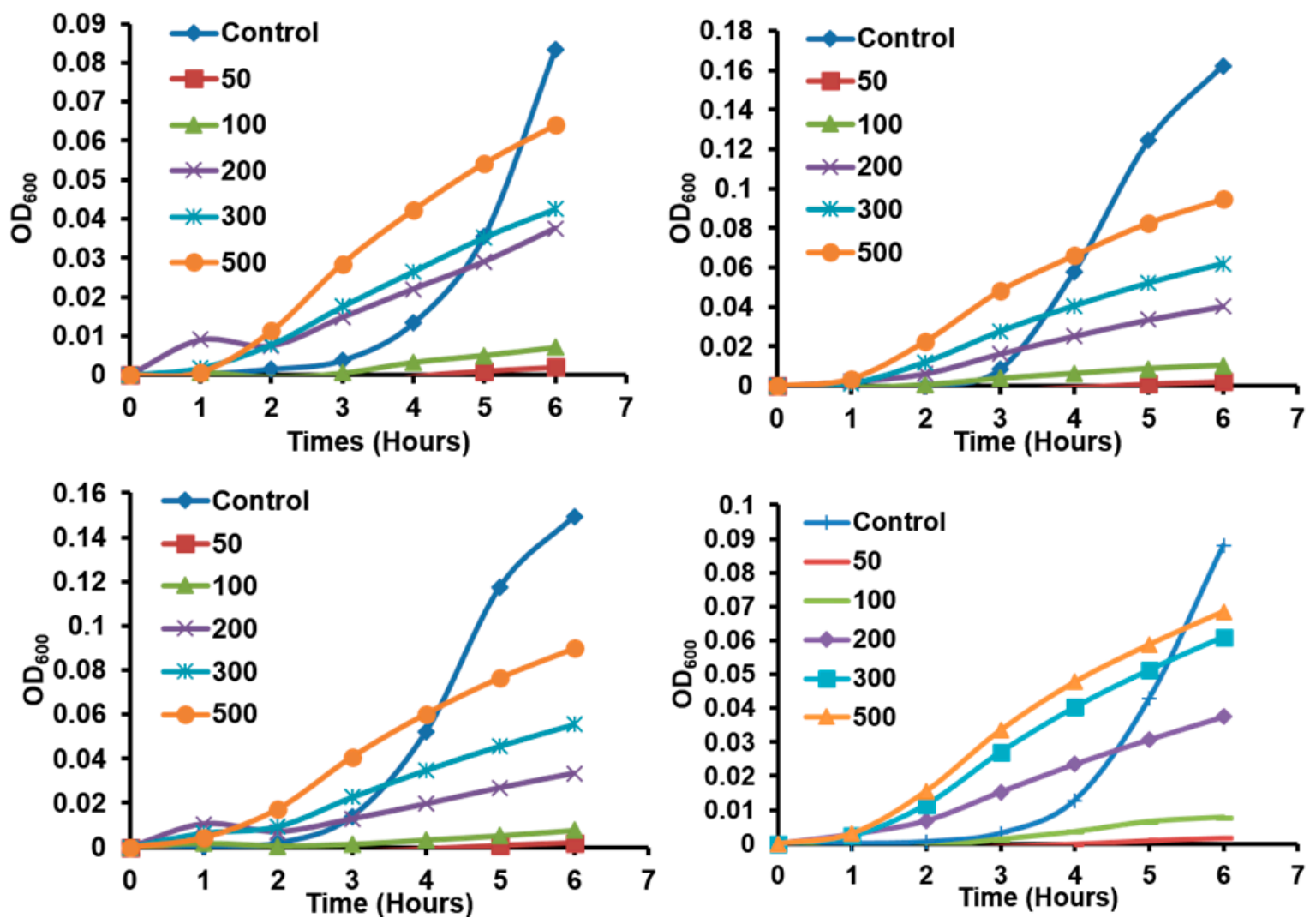

Figure 8. Antibacterial activity of Ag NPs prepared from NSE using $5 \mathrm{~mL}$ of NSE and $10 \mathrm{mM}$ of $\mathrm{AgNO}_{3}$ (NSE-Ag-1) against different bacterial strains.
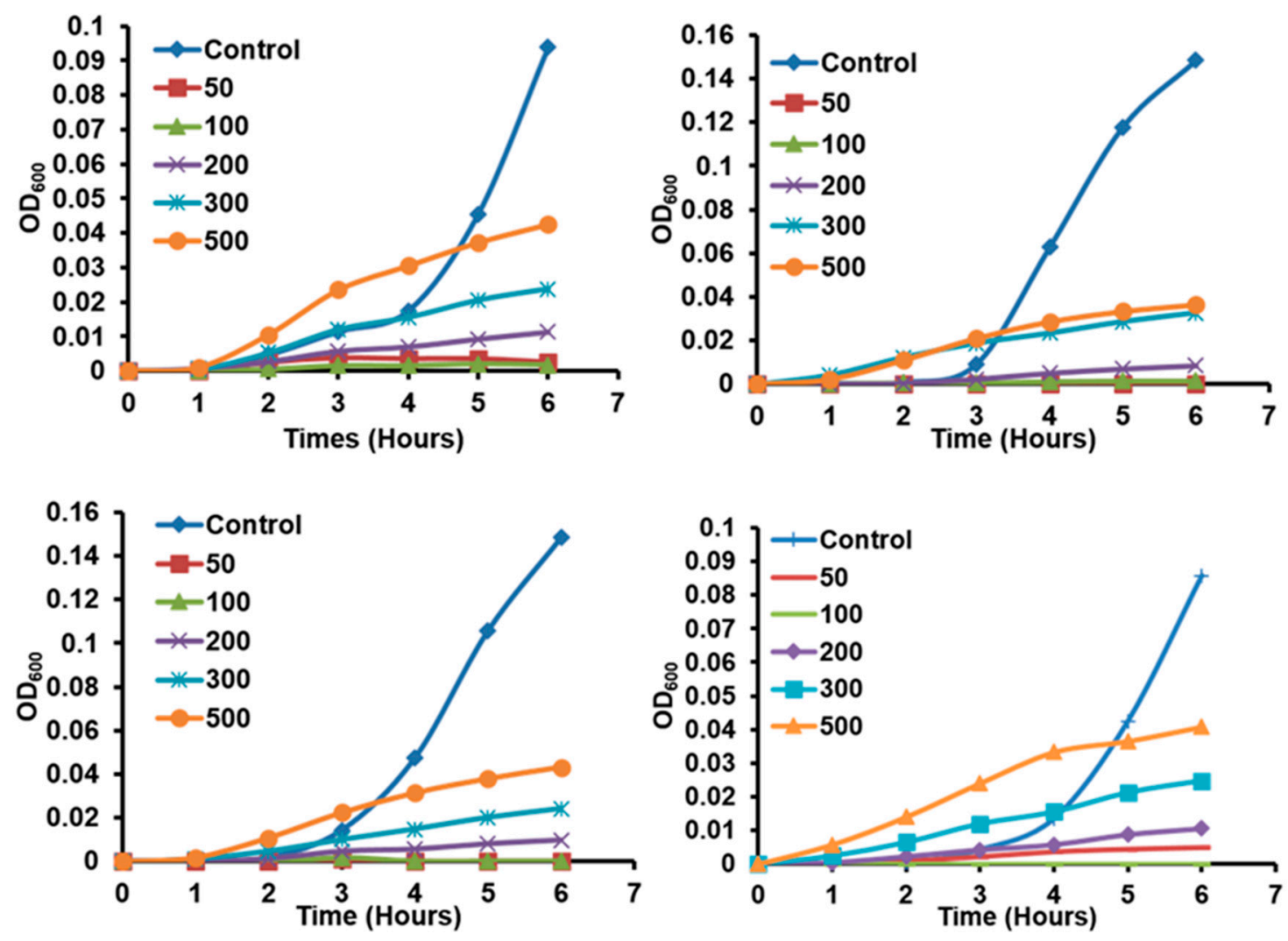

Figure 9. Antibacterial activity of Ag NPs prepared from NSE using $10 \mathrm{~mL}$ of NSE and $10 \mathrm{mM}$ of $\mathrm{AgNO}_{3}$ (NSE-Ag-2) against different bacterial strains. 


\section{Conclusions}

Here, we have successfully demonstrated a green approach for the synthesis of silver NPs employing two different aqueous extracts of Zingiber officinale (ginger) and Nigella sativa L. seeds (black cumin). This method led to the formation of less agglomerated and smaller-sized Ag NPs with enhanced antimicrobial activities. Notably, methods employing high concentrations of the extracts $(10 \mathrm{~mL})$ produced superior-quality Ag NPs (smaller size) when compared to a method in which low concentrations $(5 \mathrm{~mL})$ of the extract were used. The enhanced antibacterial activity of PE-capped silver NPs was also confirmed with the OD method, and the results consistently suggested a higher toxicity for Gram-negative (Escherichia coli and Pseudomonas aeruginosa) than for Gram-positive (Staphylococcus aureus and Bacillus subtilis) bacteria. In addition, Ag NPs obtained from GE (GE-Ag) demonstrated higher antibacterial properties when compared to the samples obtained from NSE (NSE-Ag). In this case, the higher activity was ascribed to the presence of residual phytomolecules of GE as stabilizing agents, which might have exerted a synergistic effect that enhanced the ensuing bactericidal properties. As the aqueous NSE extract exhibited only mild intrinsic antibacterial properties, the NSE-Ag demonstrated comparably lower bactericidal properties than the GE-Ag with respect to the studied bacteria. Therefore, green synthesis of NPs will help in developing ecofriendly and cheap antimicrobial agents as an alternative to conventionally used antimicrobial agents. However, to study the synergistic effects of components on the biological properties of resulting NPs, further research is highly recommended.

Supplementary Materials: The following are available online at http://www.mdpi.com/2071-1050/12/24/10523/s1: Figure S1: Fourier-transform infrared (FT-IR) spectra of NSE and GE extracts, Figure S2: EDS spectra of green synthesized Ag NPs prepared by using low (5 mL (5\% v/v), GE-Ag-1 and NSE-Ag-1) and high concentration $(10 \mathrm{~mL}(10 \% v / v)$, GE-Ag-2 and NSE-Ag-2) of GE and NSE extracts.

Author Contributions: H.Z.A. and M.R.H.S. designed the project; A.H.A., H.A.A.-A. and M.K. (Mujeeb Khan), helped to write the manuscript; A.H.A. performed the experiments and some parts of the characterization; M.A. and A.A. (Aws Alshamsan) analyzed the antibacterial activity; H.Z.A. and M.R.H.S. provided scientific guidance for successful completion of the project and helped to draft the manuscript; M.K. (Merajuddin Khan) and A.A. (Abdullah AlDobiy) performed the characterization during the revision of manuscript. All authors have read and agreed to the published version of the manuscript.

Funding: The authors extend their appreciation to the Deanship of Scientific Research at King Saud University for funding this work through the research group No. RG-1438-077.

Conflicts of Interest: The authors declare no conflict of interest.

\section{References}

1. Hussein, A.K. Applications of nanotechnology to improve the performance of solar collectors-Recent advances and overview. Renew. Sust. Energ. Rev. 2016, 62, 767-792. [CrossRef]

2. Zhang, K.; Gao, H.; Deng, R.; Li, J. Emerging Applications of Nanotechnology for Controlling Cell-Surface Receptor Clustering. Angew. Chem. Int. Ed. 2019, 58, 4790-4799. [CrossRef]

3. Mozaffari, S.; Li, W.; Dixit, M.; Seifert, S.; Lee, B.; Kovarik, L.; Mpourmpakis, G.; Karim, A.M. The role of nanoparticle size and ligand coverage in size focusing of colloidal metal nanoparticles. Nanoscale Adv. 2019, 1, 4052-4066. [CrossRef]

4. Mozaffari, S.; Li, W.; Thompson, C.; Ivanov, S.; Seifert, S.; Lee, B.; Kovarik, L.; Karim, A.M. Colloidal nanoparticle size control: Experimental and kinetic modeling investigation of the ligand-metal binding role in controlling the nucleation and growth kinetics. Nanoscale 2017, 9, 13772-13785. [CrossRef]

5. Alphandéry, E. Natural Metallic Nanoparticles for Application in Nano-Oncology. Int. J. Mol. Med. Sci. 2020, 21, 4412. [CrossRef]

6. Kim, M.; Lee, J.H.; Nam, J.M. Plasmonic photothermal nanoparticles for biomedical applications. Adv. Sci. 2019, 6, 1900471. [CrossRef]

7. Anderson, S.D.; Gwenin, V.V.; Gwenin, C.D. Magnetic functionalized nanoparticles for biomedical, drug delivery and imaging applications. Nanoscale Res. Lett 2019, 14, 1-16. [CrossRef] 
8. Azharuddin, M.; Zhu, G.H.; Das, D.; Ozgur, E.; Uzun, L.; Turner, A.P.; Patra, H.K. A repertoire of biomedical applications of noble metal nanoparticles. Chem. Commun. 2019, 55, 6964-6996. [CrossRef]

9. Ghasemi, H.; Aghabarari, B.; Alizadeh, M.; Khanlarkhani, A.; Abu-Zahra, N. High efficiency decolorization of wastewater by Fenton catalyst: Magnetic iron-copper hybrid oxides. J. Water Process Eng. 2020, 37, 101540. [CrossRef]

10. Li, W.; Ivanov, S.; Mozaffari, S.; Shanaiah, N.; Karim, A.M. Palladium acetate trimer: Understanding its ligand-induced dissociation thermochemistry using isothermal titration calorimetry, X-ray absorption fine structure, and 31p nuclear magnetic resonance. Organometallics 2018, 38, 451-460. [CrossRef]

11. Dhand, C.; Dwivedi, N.; Loh, X.J.; Ying, A.N.J.; Verma, N.K.; Beuerman, R.W.; Lakshminarayanan, R.; Ramakrishna, S. Methods and strategies for the synthesis of diverse nanoparticles and their applications: A comprehensive overview. RSC Adv. 2015, 5, 105003-105037. [CrossRef]

12. Adil, S.F.; Assal, M.E.; Khan, M.; Al-Warthan, A.; Siddiqui, M.R.H.; Liz-Marzán, L.M. Biogenic synthesis of metallic nanoparticles and prospects toward green chemistry. Dalton Trans. 2015, 44, 9709-9717. [CrossRef]

13. Mohammadinejad, R.; Shavandi, A.; Raie, D.S.; Sangeetha, J.; Soleimani, M.; Hajibehzad, S.S.; Thangadurai, D.; Hospet, R.; Popoola, J.O.; Arzani, A. Plant molecular farming: Production of metallic nanoparticles and therapeutic proteins using green factories. Green Chem. 2019, 21, 1845-1865. [CrossRef]

14. Asimuddin, M.; Shaik, M.R.; Fathima, N.; Afreen, M.S.; Adil, S.F.; Siddiqui, R.H.; Jamil, K.; Khan, M. Study of Antibacterial Properties of Ziziphus mauritiana based Green Synthesized Silver Nanoparticles against Various Bacterial Strains. Sustainability 2020, 12, 1484. [CrossRef]

15. Shaik, M.R.; Khan, M.; Kuniyil, M.; Al-Warthan, A.; Alkhathlan, H.Z.; Siddiqui, M.R.H.; Shaik, J.P.; Ahamed, A.; Mahmood, A.; Khan, M. Plant-extract-assisted green synthesis of silver nanoparticles using Origanum vulgare L. extract and their microbicidal activities. Sustainability 2018, 10, 913. [CrossRef]

16. Shaik, M.R.; Albalawi, G.H.; Khan, S.T.; Khan, M.; Adil, S.F.; Kuniyil, M.; Al-Warthan, A.; Siddiqui, M.R.H.; Alkhathlan, H.Z.; Khan, M. "Miswak" based green synthesis of silver nanoparticles: Evaluation and comparison of their microbicidal activities with the chemical synthesis. Molecules 2016, 21, 1478. [CrossRef]

17. Khan, M.; Shaik, M.R.; Adil, S.F.; Khan, S.T.; Al-Warthan, A.; Siddiqui, M.R.H.; Tahir, M.N.; Tremel, W. Plant extracts as green reductants for the synthesis of silver nanoparticles: Lessons from chemical synthesis. Dalton Trans. 2018, 47, 11988-12010. [CrossRef]

18. Amooaghaie, R.; Saeri, M.R.; Azizi, M. Synthesis, characterization and biocompatibility of silver nanoparticles synthesized from Nigella sativa leaf extract in comparison with chemical silver nanoparticles. Ecotoxicol. Environ. Saf. 2015, 120, 400-408. [CrossRef]

19. Alkhalaf, M.I.; Hussein, R.H.; Hamza, A. Green synthesis of silver nanoparticles by Nigella sativa extract alleviates diabetic neuropathy through anti-inflammatory and antioxidant effects. Saudi J. Biol. Sci. 2020, 27, 2410-2419. [CrossRef]

20. Chrysant, S.G.; Chrysant, G.S. Herbs used for the treatment of hypertension and their mechanism of action. Curr. Hypertens. Rep. 2017, 19, 77. [CrossRef] [PubMed]

21. Macwan, S.R.; Dabhi, B.K.; Aparnathi, K.; Prajapati, J. Essential oils of herbs and spices: Their antimicrobial activity and application in preservation of food. Int. J. Curr. Microbiol. Appl. Sci. 2016, 5, 885-901. [CrossRef]

22. Jessica Elizabeth, D.L.T.; Gassara, F.; Kouassi, A.P.; Brar, S.K.; Belkacemi, K. Spice use in food: Properties and benefits. Crit. Rev. Food Sci. Nutr. 2017, 57, 1078-1088. [CrossRef] [PubMed]

23. Arablou, T.; Aryaeian, N. The effect of ginger (Zingiber officinale) as an ancient medicinal plant on improving blood lipids. J. Herb. Med. 2018, 12, 11-15. [CrossRef]

24. Khan, M.; Ullah, N.; Azhar, M.; Komal, W.; Muhammad, W. A mini-review on the therapeutic potential of Zingiber officinale (ginger). Nat. Prod. Ind. J. 2019, 15, 125.

25. Kim, Y.-S.; Hong, C.S.; Lee, S.W.; Nam, J.H.; Kim, B.J. Effects of ginger and its pungent constituents on transient receptor potential channels. Int. J. Mol. Med. 2016, 38, 1905-1914. [CrossRef]

26. Akintobi, O.; Onoh, C.; Ogele, J.; Idowu, A.; Ojo, O.; Okonko, I. Antimicrobial activity of Zingiber officinale (ginger) extract against some selected pathogenic bacteria. Nat. Sci. 2013, 11, 7-15.

27. Ahmad, A.; Husain, A.; Mujeeb, M.; Khan, S.A.; Najmi, A.K.; Siddique, N.A.; Damanhouri, Z.A.; Anwar, F. A review on therapeutic potential of Nigella sativa: A miracle herb. Asian Pac. J. Trop. Biomed. 2013, 3, 337-352. [CrossRef]

28. Hosseinzadeh, H.; Fazly Bazzaz, B.; Haghi, M.M. Antibacterial activity of total extracts and essential oil of Nigella sativa L. seeds in mice. Pharmacologyonline 2007, 2, 429-435. 
29. Burdușel, A.-C.; Gherasim, O.; Grumezescu, A.M.; Mogoantă, L.; Ficai, A.; Andronescu, E. Biomedical applications of silver nanoparticles: An up-to-date overview. Nanomaterials 2018, 8, 681. [CrossRef]

30. Rajan, R.; Chandran, K.; Harper, S.L.; Yun, S.-I.; Kalaichelvan, P.T. Plant extract synthesized silver nanoparticles: An ongoing source of novel biocompatible materials. Ind. Crops Prod. 2015, 70, 356-373. [CrossRef]

31. Park, Y. A new paradigm shift for the green synthesis of antibacterial silver nanoparticles utilizing plant extracts. Toxicol. Res. 2014, 30, 169-178. [CrossRef] [PubMed]

32. Khan, M.; Khan, M.; Adil, S.F.; Tahir, M.N.; Tremel, W.; Alkhathlan, H.Z.; Al-Warthan, A.; Siddiqui, M.R.H. Green synthesis of silver nanoparticles mediated by Pulicaria glutinosa extract. Int. J. Nanomed. 2013, 8, 1507.

33. Khan, M.; Al-Hamoud, K.; Liaqat, Z.; Shaik, M.R.; Adil, S.F.; Kuniyil, M.; Alkhathlan, H.Z.; Al-Warthan, A.; Siddiqui, M.R.H.; Mondeshki, M. Synthesis of Au, Ag, and Au-Ag Bimetallic Nanoparticles Using Pulicaria undulata Extract and Their Catalytic Activity for the Reduction of 4-Nitrophenol. Nanomaterials 2020, 10, 1885. [CrossRef] [PubMed]

34. Marslin, G.; Selvakesavan, R.K.; Franklin, G.; Sarmento, B.; Dias, A.C. Antimicrobial activity of cream incorporated with silver nanoparticles biosynthesized from Withania somnifera. Int. J. Nanomed. 2015, 10, 5955.

35. Awwad, A.M.; Salem, N.M.; Abdeen, A.O. Green synthesis of silver nanoparticles using carob leaf extract and its antibacterial activity. Int. J. Indus. Chem. 2013, 4, 29. [CrossRef]

36. Mallikarjuna, K.; Sushma, N.J.; Reddy, B.S.; Narasimha, G.; Raju, B.D.P. Palladium nanoparticles: Single-step plant-mediated green chemical procedure using Piper betle leaves broth and their anti-fungal studies. Int. J. Chem. Anal. Sci. 2013, 4, 14-18. [CrossRef]

37. Khan, M.; Khan, S.T.; Khan, M.; Adil, S.F.; Musarrat, J.; Al-Khedhairy, A.A.; Al-Warthan, A.; Siddiqui, M.; Alkhathlan, H.Z. Antibacterial properties of silver nanoparticles synthesized using Pulicaria glutinosa plant extract as a green bioreductant. Int. J. Nanomed. 2014, 9, 3551-3565.

38. Erci, F.; Cakir-Koc, R.; Isildak, I. Green synthesis of silver nanoparticles using Thymbra spicata L. var. spicata (zahter) aqueous leaf extract and evaluation of their morphology-dependent antibacterial and cytotoxic activity. Artif. Cells Nanomed. Biotechnol. 2018, 46, 150-158. [CrossRef]

39. Yeh, H.-Y.; Chuang, C.-H.; Chen, H.-C.; Wan, C.-J.; Chen, T.-L.; Lin, L.-Y. Bioactive components analysis of two various gingers (Zingiber officinale Roscoe) and antioxidant effect of ginger extracts. LWT-Food Sci. Technol. 2014, 55, 329-334. [CrossRef]

40. Mashhadian, N.; Rakhshandeh, H. Antibacterial and antifungal effects of Nigella sativa extracts against $\mathrm{S}$. aureus, P. aeroginosa and C. albicans. Pak. J. Med. Sci. 2005, 21, 47-52.

Publisher's Note: MDPI stays neutral with regard to jurisdictional claims in published maps and institutional affiliations.

(C) 2020 by the authors. Licensee MDPI, Basel, Switzerland. This article is an open access article distributed under the terms and conditions of the Creative Commons Attribution (CC BY) license (http://creativecommons.org/licenses/by/4.0/). 